Article

\title{
Inhibition Effect of Graphene Nanoplatelets on Electrical Degradation in Silicone Rubber
}

\author{
Tao Han ${ }^{1, *} \mathbb{D}$, Boxue Du ${ }^{1, *}$, Jingang $\mathrm{Su}^{1}{ }^{1}$, Yu Gao ${ }^{1, *}$, Yunqi Xing ${ }^{2, *} \mathbb{C}$, Shengchen Fang ${ }^{1,3}$, \\ Chuanyang $\mathrm{Li}^{4}$ and Zhipeng Lei ${ }^{4}$ \\ 1 Key Laboratory of Smart Grid of Education Ministry, School of Electrical and Information Engineering, \\ Tianjin University, Tianjin 300072, China; sujg1357@126.com (J.S.); fangscm@126.com (S.F.) \\ 2 State Key Laboratory of Reliability and Intelligence of Electrical Equipment, Hebei University of Technology, \\ Tianjin 300130, China \\ 3 State Grid Tianjin Electric Power Research Institute, Tianjin 300384, China \\ 4 Department of Electrical Engineering, University of Bologna, 40134 Bologna, Italy; \\ lichuanyangsuper@163.com (C.L.); leizhipeng@163.com (Z.L.) \\ * Correspondence: hant@tju.edu.cn (T.H.); duboxue@tju.edu.cn (B.D.); hmgaoyu@tju.edu.cn (Y.G.); \\ yqxing@hebut.edu.cn (Y.X.)
}

Received: 24 April 2019; Accepted: 27 May 2019; Published: 3 June 2019

\begin{abstract}
Silicone rubber (SIR) is widely used as an insulation material in high voltage cable accessories. Electrical tree is a typical electrical degradation and is easily initiated because of the distorted electric field. In this study, graphene nanoplatelets at contents of $0.001-0.010 \mathrm{wt} \%(0.00044-0.00436 \mathrm{vol} \%)$ were added into SIR to improve the electrical tree inhibiting ability. Scanning electron microscopy, conductivity and surface potential decay tests were conducted to analyze the characteristics of graphene/SIR nanocomposites. The typical electrical treeing experiment was employed to observe the electrical tree inhibition of graphene in SIR. The results show that graphene nanoplatelets were well dispersed in SIR. The conductivity was higher after the addition of graphene nanoplatelets, and the trap distribution was affected by graphene nanoplatelets. The tree was changed from a bush-branch structure to a bush structure after the addition of graphene. Tree inception voltage improved and reached the highest mean value at $0.003 \mathrm{wt} \%$. The tree length was inhibited at 0.001 to $0.007 \mathrm{wt} \%$ and the lowest tree length occurred at $0.005 \mathrm{wt} \%$.
\end{abstract}

Keywords: electrical degradation; electrical tree; graphene; SIR; nanocomposites; inhibition

\section{Introduction}

Silicone rubber (SIR) is usually employed as insulation in both alternating current (AC) and direct current (DC) power cable accessories, forming a multilayer insulation with cross-linked polyethylene (XLPE), polypropylene (PP) or other polymers [1-3]. Given the distortion of electric field and manufacturing defects, electrical degradation is easily initiated in SIR [4-6]. As a typical electrical degradation, the electrical tree initiation and growth have been widely researched since it was first identified [7-10].

Nanodielectrics with filler contents of several wt \% have been proven to have a high electrical tree-inhibiting ability [11-14]. Traditional inorganic nanoparticles have also been used to improve the tree resistance of SIR, including silica $\left(\mathrm{SiO}_{2}\right)$ and alumina $\left(\mathrm{Al}_{2} \mathrm{O}_{3}\right)$ [15-17]. With a high enough content (lower than $10 \mathrm{wt} \%$ ) of nanoparticles, trees are considerably inhibited [15-17]. The multi-core model proposed by Tanaka et al. explained the inhibition effect of nanoparticles on electrical trees [18]. According to this model, the multilayer structure around the nanoparticle produces a number of traps, which capture the injected space charges and uniform the electric field in nanocomposites. It has been 
verified that the particles with higher dielectric strength will inhibit tree growth and act as tree barriers, as reviewed by Danikas et al. $[19,20]$. From this perspective, one effective method to inhibit electrical trees is to create a huge interface between the nanofillers and matrix. It can be inferred that the optimal content of nanofillers with a two-dimensional (2D) structure may be much lower than the traditional nanofillers because of the high specific surface area (SSA).

Graphene is a typical 2D structure with a giant specific surface area. The effects of graphene nanoplatelets on SIR properties have been researched [21-24]. In these studies, several wt \% of graphene or graphene oxide nanoplatelets were added into SIR to improve the thermal or mechanical properties. However, the conductivity of SIR was increased by several orders of magnitude with the content of this fillgrade of graphene, which is bad for an insulation material [21,22]. For the insulation properties, it was found that a content lower than $0.01 \mathrm{wt} \%$ increases trap levels in graphene/low-density polyethylene (LDPE) nanocomposites [25]. With a higher content of $0.01 \%$, the positive effect disappears [25]. Graphene at a content of $0.005 \mathrm{wt} \%$ could markedly suppress the space charge injection and accumulation in LDPE [26]. In the treeing process, the trap level and space charge also play important roles [27]. However, the effect of graphene on electrical trees in SIR has not yet been reported.

In this work, graphene/SIR nanocomposites were prepared with filler contents of 0,0.001, 0.003, $0.005,0.007$ and $0.010 \mathrm{wt} \%$. Scanning electron microscopy (SEM), conductivity and trap distribution were tested. The electrical treeing experiment was conducted and the inhibition effect of graphene was discussed.

\section{Materials and Methods}

\subsection{Preparation of Graphene/SIR Nanocomposites}

High temperature vulcanized methyl vinyl SIR (MVQ 110-2) was provided by Dongjue Silicone Group Co. Ltd. (Nanjing, China). Its average molecular weight was $65 \times 10^{4} \mathrm{~g} / \mathrm{mol}$, and the content of vinyl groups was $0.13-0.20 \mathrm{~mol} \%$. The graphene used for the sample was purchased from Tanfeng Graphene Technology Co., Ltd. (Nanjing, China). The diameter of graphene nanoplatelets was $0.5-5 \mu \mathrm{m}$, the thickness was $0.5-3.0 \mathrm{~nm}$, with $1-2$ layers and an SSA of $1000-1217 \mathrm{~m}^{2} / \mathrm{g}$. Before mixing, a surface treatment was applied on the graphene.

Zhang et al. reported that graphene modified with vinyltrimethoxysilane exhibited improved dispersing and banding properties with SIR [22]. Thus, vinyltrimethoxysilane (VTMS, Henan Tianfu Chemical Co., Ltd., Zhengzhou, China) was used as the surfactant for surface treatment. The procedures were as follows: In the first step, the graphene was dispersed into ethanol for $30 \mathrm{~min}$. Then, magnetic stirring was conducted for $10 \mathrm{~h}$ at $60^{\circ} \mathrm{C}$. The mass ratio of the VTMS to graphene was 1.5:1 [22]. Then, magnetic stirring was carried out for $10 \mathrm{~h}$ at $60^{\circ} \mathrm{C}$. Subsequently, the mixture was filtered and washed several times with methanol. After this, the surface-modified graphene was placed into a vacuum oven at $80^{\circ} \mathrm{C}$ for $12 \mathrm{~h}$ to be dried.

The weight content of graphene in nanocomposites was $0,0.001,0.003,0.005,0.007$ and $0.010 \mathrm{wt}$ $\%(0,0.00044,0.00132,0.00219,0.00307$ and $0.00436 \mathrm{vol} \%$, respectively). The required graphene was weighed by a microbalance with a sensitivity of $0.01 \mathrm{mg}$ (CPA225D, Sartorius AG, Göttingen, Germany). A twin-screw continuous mixer was employed to mix the graphene and SIR, with a rotation speed of $40 \mathrm{rpm}$ at room temperature for $15 \mathrm{~min}$. Then 2,5-dimethyl-2,5-di(tert-butylperoxy) hexane (DBPMH, Dongguan Tengkai Rubber and Plastic Technology Co., Ltd., Dongguan, China) was added into the mixture as the vulcanizing agent at $1.5 \mathrm{phr}$. After the mixing process, the compounds were placed into the moulding in the plate vulcanizing machine (XLBD-100T, Nanjing Mixer Industrial Co. Ltd. Nanjing, China) at a temperature of $165^{\circ} \mathrm{C}$ and pressure of $10 \mathrm{MPa}$ for $10 \mathrm{~min}$ [21]. After this, the vulcanized specimen with the dimension of $90 \times 90 \times 3 \mathrm{~mm}$ was placed in an oven at $180{ }^{\circ} \mathrm{C}$ for $3 \mathrm{~h}$ for the second step of vulcanization. 


\subsection{Morphology Analysis of Nanocomposites}

A high-resolution scanning electron microscope (SEM, FEI SCIOS, Thermo Fisher Scientific, Waltham, Massachusetts, NY, USA) was employed to observe the cross-section of the graphene/SIR nanocomposites. The samples were cryo-fractured in liquid nitrogen and the surface of the cross-section was painted with platinum before scanning.

\subsection{Conductivity Measurement}

DC conductivity was tested on a typical three-electrode system as in [28]. The sample for the DC conductivity test had a radius of $1.25 \mathrm{~cm}$ and thickness of $700 \mu \mathrm{m}$. Given the increase of conductivity with temperature and electric field [29], the conductivity under fixed temperature and electric field was employed here to analyze the effect of graphene. In this test, the voltage was $3000 \mathrm{~V}$ and temperature was $20^{\circ} \mathrm{C}$. The ampere meter for the current test was a Keithley $6517 \mathrm{~b}$ (Keithley Instruments, Cleveland, $\mathrm{OH}, \mathrm{USA})$.

After 10,000 s, the conductivity was calculated as follows:

$$
\sigma=\frac{I}{U} \cdot \frac{l}{\pi r^{2}}
$$

where $I$ is the current in $\mathrm{A}, U$ is the applied voltage in $\mathrm{V}, l$ is the thickness of sample in $\mathrm{m}$ and $r$ is the radius of sample in $\mathrm{m}$.

\subsection{Surface Potential Decay and Trap Distribution Measurement}

To calculate the trap distribution in SIR, surface potential decay (SPD) measurement was used. The measurement setup was shown in our previous work [25]. The sample for the SPD test was round in shape with a radius of $20 \mathrm{~mm}$ and thickness of $300 \mu \mathrm{m}$. Before the test, the surface of the sample was charged by DC corona. The voltage applied on the needle electrode was $-7 \mathrm{kV} \mathrm{DC}$. After the $15-\mathrm{min}$ charging process, the sample was moved to the probe of the electrostatic voltmeter (Trek 347-3HCE, TREK, Inc., New York, NY, USA). The probe was positioned $3 \mathrm{~mm}$ above the center of the sample surface. The decay of surface potential was recorded by an electrostatic voltmeter. The temperature of the sample was maintained at $20{ }^{\circ} \mathrm{C}$, and the relative humidity was controlled at $25 \%$.

The potential decay rate is related to the trap distribution in samples. The trap energy and density can be calculated by these three equations [25,30]:

$$
\begin{gathered}
E_{\mathrm{T}}=k_{\mathrm{B}} T \ln \left(v_{\mathrm{ATE}} t\right), \\
v_{\mathrm{ATE}}=\frac{k_{\mathrm{B}} T}{h}, \\
N_{\mathrm{T}}=\frac{4 \varepsilon_{0} \varepsilon_{r}}{q k_{\mathrm{B}} T L^{2}}\left|t \frac{d U_{s}}{d t}\right|,
\end{gathered}
$$

where $E_{\mathrm{T}}$ is the trap energy in $\mathrm{eV} ; \mathrm{T}$ is the temperature in $\mathrm{K} ; v_{\mathrm{ATE}}$ is the attempt to escape frequency in $\mathrm{s}^{-1} ; k_{\mathrm{B}}$ is the Boltzmann's constant in $\mathrm{eV} / \mathrm{K} ; h$ is the Planck constant in $\mathrm{eV} \cdot \mathrm{s} ; N_{\mathrm{T}}$ is the trap density in $\mathrm{eV}^{-1} \mathrm{~m}^{-3} ; \varepsilon_{0}$ and $\varepsilon_{r}$ are the permittivity of vacuum and the relative permittivity of SIR; $q$ is the elementary charge in $C$; $L$ is the sample thickness in $\mathrm{m} ; U_{s}$ is the surface potential in $\mathrm{V}$ and $t$ is the decay time in $\mathrm{s}$.

\subsection{Electrical Treeing Experiments}

The treeing test setup is shown in Figure 1. The size of sample was $40 \times 20 \mathrm{~mm}$, with a thickness of $3 \mathrm{~mm}$. During the test, high voltage was applied by a transformer (YDJ/TDM-2/50, Sanxin Electrical Equipments, Wuhan, China). The frequency of the AC voltage was $50 \mathrm{~Hz}$ and the root-mean-square (RMS) varied from 5 to $10 \mathrm{kV}$. The voltage increase rate was $1 \mathrm{kV} / \mathrm{s}$. A needle electrode was inserted 
into samples as the high voltage electrode. The curvature radius of the needle tip was $3 \mu \mathrm{m}$. The needle was chosen using a microscope before it was employed. The distance from the needle tip to the edge of the sample was set to $2 \mathrm{~mm}$. A copper foil was attached to the bottom of sample as the ground electrode during the test. A resistor was connected in the test circuit for protection of the transformer. The treeing process was recorded by a digital microscope (XDC10A, KENI, Shenzhen Sangnond Technology Co., Ltd., Shenzhen, China). The treeing time was set to $1 \mathrm{~h}$ with each voltage. The temperature was $20^{\circ} \mathrm{C}$.
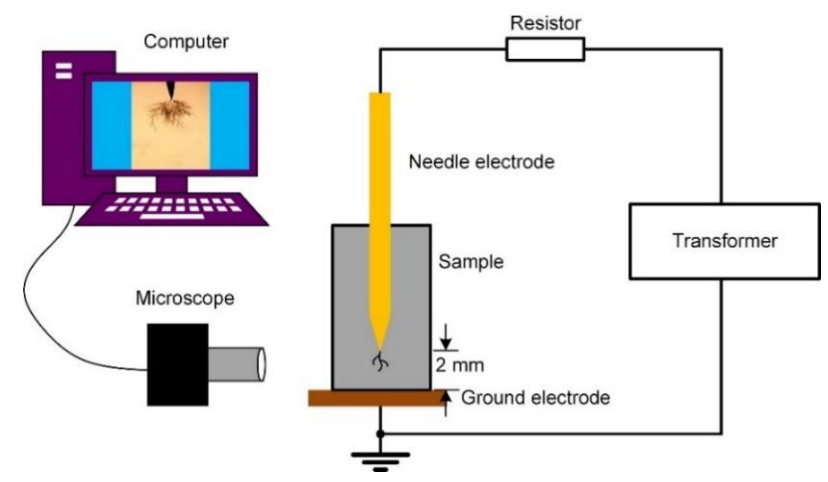

Figure 1. Treeing experiment setup.

\section{Results}

\subsection{Morphology and SEM}

The graphene nanoplatelets distribution in the samples for all graphene contents were analyzed with SEM. The SEM pictures of samples with $0.001,0.005$ and $0.010 \mathrm{wt} \%$ are shown in Figure 2. Figure $2 \mathrm{a}, \mathrm{b}$ shows the SEM images of nanocomposites with $0.001 \mathrm{wt} \%$. The graphene nanoplatelets dispersed well in this sample. It should be noted that the orientation of graphene nanoplatelets would be random because no orientation inducement was employed in the preparation. Then, graphene nanoplatelets vertical to the cross-section would not be observed in SEM because of the thickness of $0.5-3 \mathrm{~nm}$. An enlarged region from Figure $2 \mathrm{a}$ is shown in Figure $2 \mathrm{~b}$. Figure $2 \mathrm{c}, \mathrm{d}$ shows the dispersion in nanocomposites with 0.005 and $0.010 \mathrm{wt} \%$. With the increase in graphene content, the distance between the graphene nanoplatelets decreased. In Figure $2 \mathrm{~d}$, some of the graphene nanoplatelets were bridged at the content $0.010 \mathrm{wt} \%$.
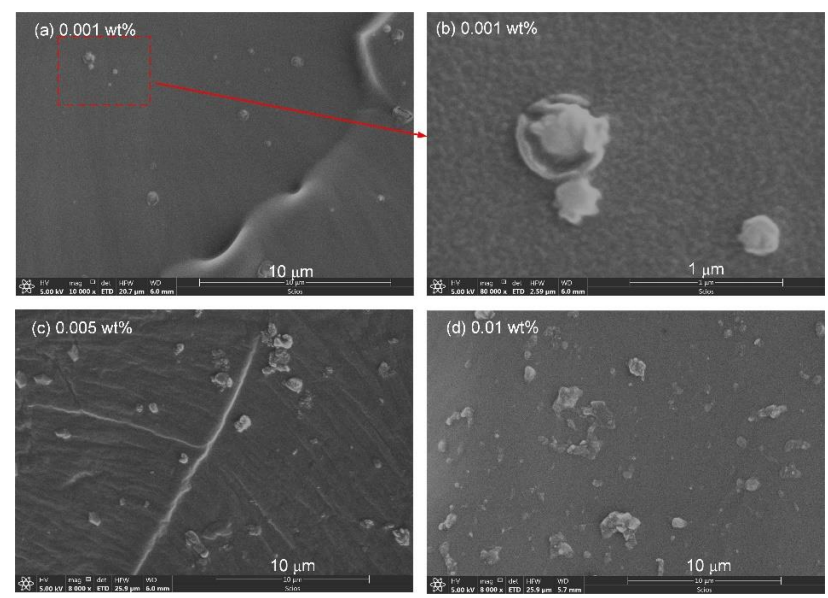

Figure 2. Scanning electron microscopy (SEM) images of different samples: (a) SEM of nanocomposites with graphene content of $0.001 \mathrm{wt} \%$; (b) Enlarged SEM of (a); (c) SEM of nanocomposites with a graphene content of $0.005 \mathrm{wt} \%$ and (d) SEM of nanocomposites with a graphene content of $0.010 \mathrm{wt} \%$. Graphene nanoplatelets with a lighter color can be found in each figure. 


\subsection{Conductivity of Graphene/SIR Nanocomposites}

The conductivity of graphene/SIR nanocomposites is shown in Figure 3. The data are calculated from five test results at each content and the standard deviations are shown in Figure 3. With the content increasing from 0 to $0.005 \mathrm{wt} \%$, the conductivity of the nanocomposites was increased by $7.06 \times 10^{-13} \mathrm{~S} / \mathrm{m}$. From 0.005 to $0.010 \mathrm{wt} \%$, a sharp increase $\left(1.55 \times 10^{-11} \mathrm{~S} / \mathrm{m}\right)$ in conductivity occurred, potentially caused by the shorter distance between graphene nanoplatelets at higher graphene contents.

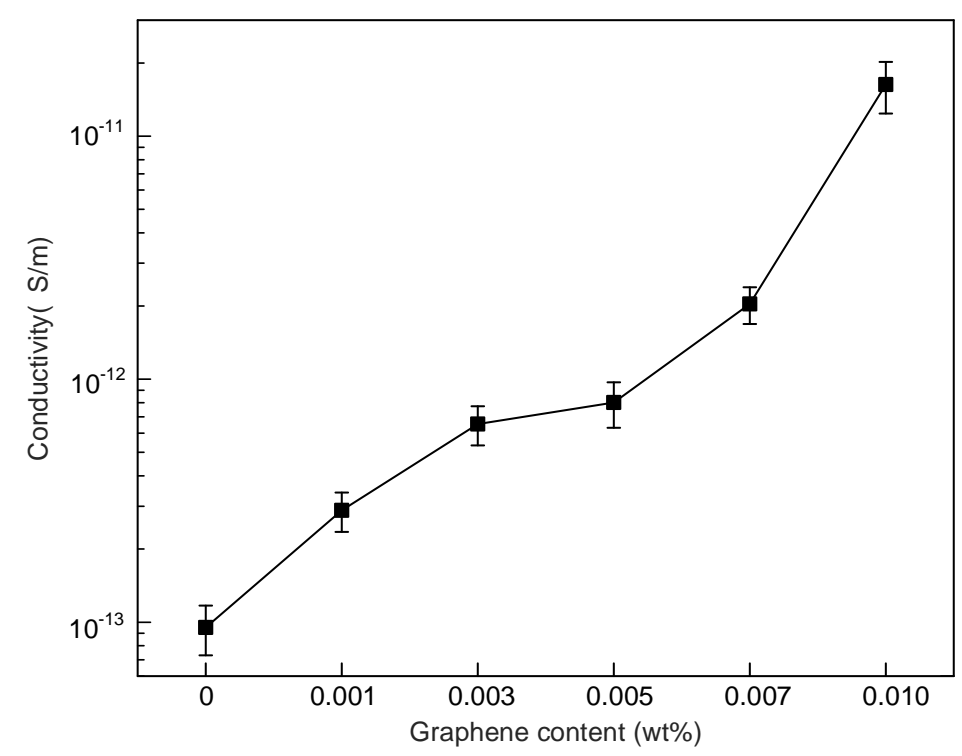

Figure 3. Conductivity of graphene/silicone rubber nanocomposites.

\subsection{SPD Characteristics and Trap Distribution of Graphene/SIR Nanocomposites}

The potential decay in graphene/SIR nanocomposites is related to the charge migration from SIR bulk [31,32]. During the SPD tests, five samples were employed for each content. The typical results at 0, 0.001, 0.005 and $0.010 \mathrm{wt} \%$ from the SPD test are shown in Figure 4. With the graphene content increasing from 0 to $0.010 \mathrm{wt} \%$, the decay rate decreased firstly and then increased.

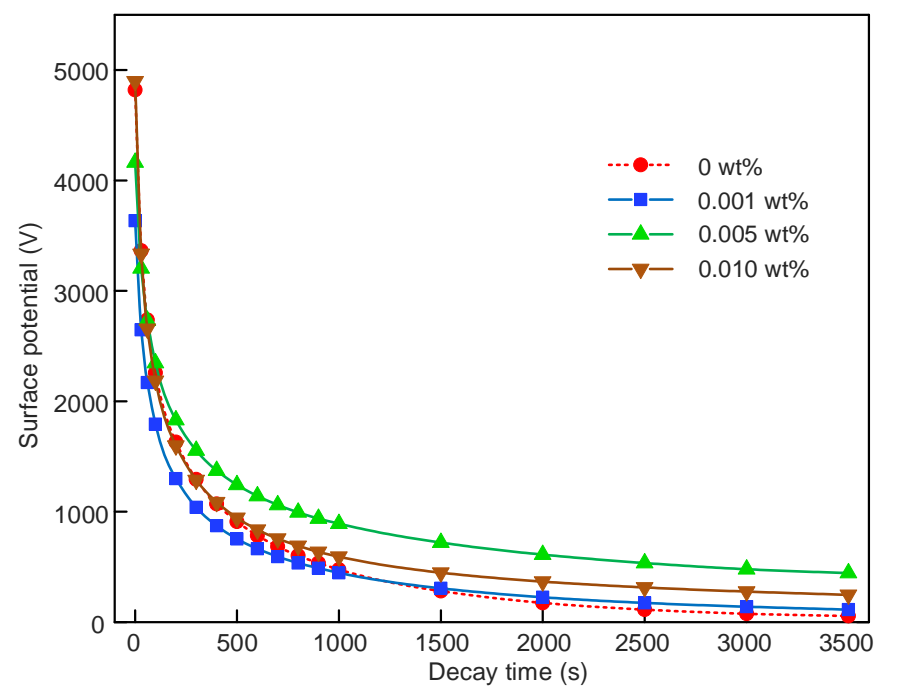

Figure 4. Surface potential decay in graphene/silicone rubber nanocomposites.

The trap distribution in the nanocomposites can be calculated according to Equations (2)-(4). The relative permittivity used here is shown in Table 1. As shown in Figure 5, the results calculated from 
data in Figure 4 are employed here to simplify the illustration. It can be found that the trap distribution characteristics were changed by the addition of graphene. There were two peaks in the trap distribution curve, defined as shallow and deep trap levels. As shown in Figure 5, both the shallow and deep trap levels shifted to the right after the addition of graphene at 0.001 and $0.005 \mathrm{wt} \%$. This indicated that it was harder for charges to detrap in nanocomposites with 0.001 and $0.005 \mathrm{wt} \%$, whereas in nanocomposites with $0.010 \mathrm{wt} \%$ graphene, the shallow trap level was lower than that of 0 wt $\%$ and the deep trap level was approximate to that of $0 \mathrm{wt} \%$. The trap density was also affected by the addition of graphene. We found that the density of the shallow trap decreased from $3.4 \times 10^{20} \mathrm{eV}^{-1} \mathrm{~m}^{-3}$ to lower than $2.7 \times 10^{20} \mathrm{eV}^{-1} \mathrm{~m}^{-3}$ and the density of deep trap decreased from $2.2 \times 10^{20} \mathrm{eV}^{-1} \mathrm{~m}^{-3}$ to lower than $1.7 \times 10^{20} \mathrm{eV}^{-1} \mathrm{~m}^{-3}$ after the addition of graphene.

Table 1. Relative permittivity results at different graphene contents.

\begin{tabular}{ccccccc}
\hline Graphene Content (wt \%) & $\mathbf{0}$ & $\mathbf{0 . 0 0 1}$ & $\mathbf{0 . 0 0 3}$ & $\mathbf{0 . 0 0 5}$ & $\mathbf{0 . 0 0 7}$ & $\mathbf{0 . 0 1 0}$ \\
\hline Relative permittivity & 3.16 & 3.05 & 3.18 & 3.19 & 3.22 & 3.28 \\
\hline
\end{tabular}

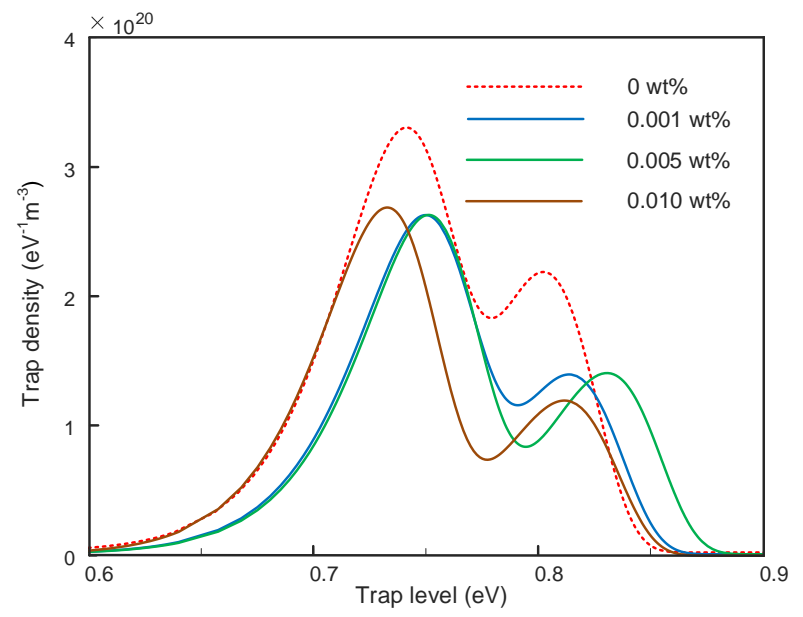

Figure 5. Trap distribution in graphene/silicone rubber nanocomposites.

\subsection{Electrical Tree in Graphene/SIR Nanocomposites}

\subsubsection{Tree Structure in Graphene/SIR Nanocomposites}

During the experiment, two different tree structures were observed, defined as bush-branch tree and bush tree. As shown in Figure 6a, the bush-branch tree had a combined structure- there was a bush structure near the needle tip and a branch area out of the bush structure. In the bush area, all the tree channels interlaced with each other, forming a totally black area. In Figure $6 \mathrm{~b}-\mathrm{f}$, all the trees are the bush structure. In the undoped SIR sample, all trees were the bush-branch structure at $60 \mathrm{~min}$. For graphene content from 0.001 to $0.007 \mathrm{wt} \%$, all the trees were typical bush structure; at the content of $0.010 \mathrm{wt} \%$, the bush tree was much longer than the others.
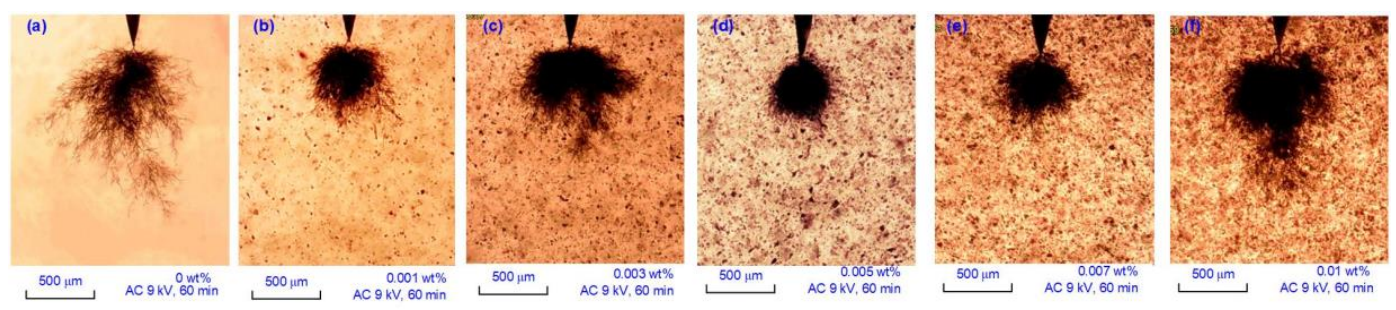

Figure 6. Tree structures at different graphene contents. (a) Bush-branch tree at $0 \mathrm{wt} \% ;(\mathbf{b}-\mathbf{f})$ bush trees at $0.001-0.010 \mathrm{wt} \%$. 


\subsubsection{Tree Inception Voltage in Graphene/SIR Nanocomposites}

To observe the inhibition effect of graphene, the tree inception voltage was tested. The RMS of the AC voltage was set to $5-10 \mathrm{kV}$. In the test, the voltage was increased in $0.2-\mathrm{kV}$ steps and was maintained for $30 \mathrm{~s}$ at each step to check if the tree was triggered or not. If an electrical tree with a length of $20 \mu \mathrm{m}$ was observed, the RMS was recorded as the tree inception voltage. Ten samples were tested for each graphene content.

The average inception voltages from 10 tests and the standard deviations are shown in Figure 7. The average inception voltage with $0 \mathrm{wt} \%$ was $6.5 \mathrm{kV}$. With the contents ranging from 0.001 to $0.007 \mathrm{wt} \%$, the inception voltage increased to around $7.0 \mathrm{kV}$. When the content increased to $0.010 \mathrm{wt} \%$, the average inception voltage decreased to $6.3 \mathrm{kV}$. The addition of graphene increased the inception voltage at contents lower than $0.007 \mathrm{wt} \%$ and decreased the inception voltage at $0.010 \mathrm{wt} \%$.

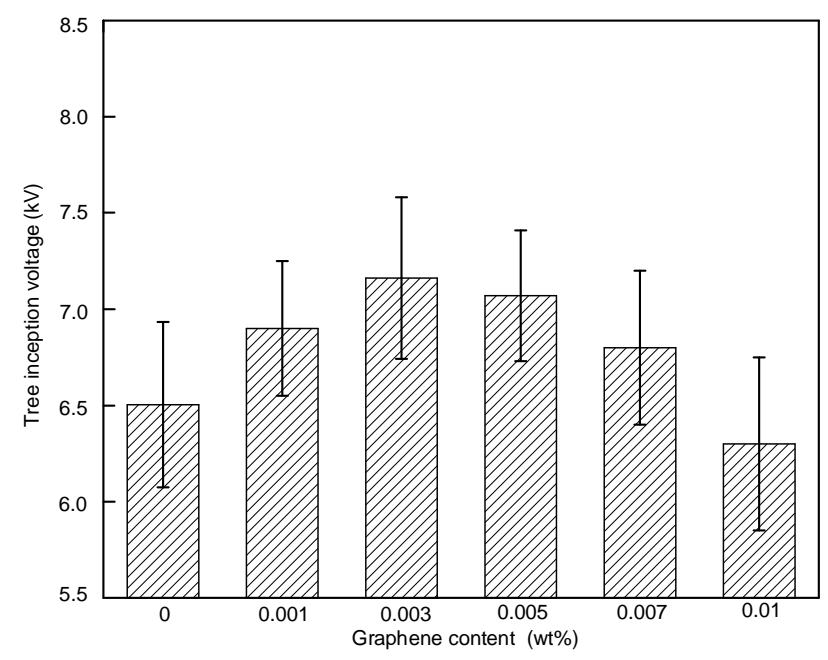

Figure 7. Tree inception voltage with different graphene contents.

\subsubsection{Tree Growth in Graphene/SIR Nanocomposites}

The treeing process was recorded using a microscope and computer. Typical tree growth processes in samples with different graphene contents are shown in Figure 8.

As shown in Figure 8a1-a5, the tree in the undoped SIR sample displayed the branch structure in the first $20 \mathrm{~min}$. Then the bush area appeared near the needle tip. All the branch channels continued growing simultaneously. At the treeing time of $60 \mathrm{~min}$, the typical bush-branch tree formed.

As shown in Figure 8b1-b5, there were many tiny branches after the tree inception. At the same treeing time in the first $5 \mathrm{~min}$, the bush tree size was much smaller than the bush-branch tree. With the increase in treeing time, the bush area became darker and the size continued to grow. However, there was no obvious length growth for this bush tree from 20 to $60 \mathrm{~min}$.

As shown in Figure 8c1-c5, a typical bush tree formed in the first $40 \mathrm{~min}$ in the sample with 0.010 wt $\%$. After this, an obvious growth of tree length occurred, making the tree much longer than that of the $0.005 \mathrm{wt} \%$.

The tree length of a typical tree without breakdown at different times was calculated as shown in Figure 9. Figure 9 shows that a fast length growth process occurred in the first three minutes. After this stage, the growth in undoped SIR and graphene/SIR nanocomposites showed different tendencies. In the undoped SIR, the tree length continued growing at a higher speed and reached $1200 \mu \mathrm{m}$ at $60 \mathrm{~min}$. In the nanocomposites with graphene contents ranging from 0.001 to $0.007 \mathrm{wt} \%$, there was no obvious growth in tree length from 10 to $60 \mathrm{~min}$. This shows that the tree length growth was inhibited by the graphene at these contents. In the sample with $0.010 \mathrm{wt} \%$, the tree length growth process was similar to that of undoped SIR. 


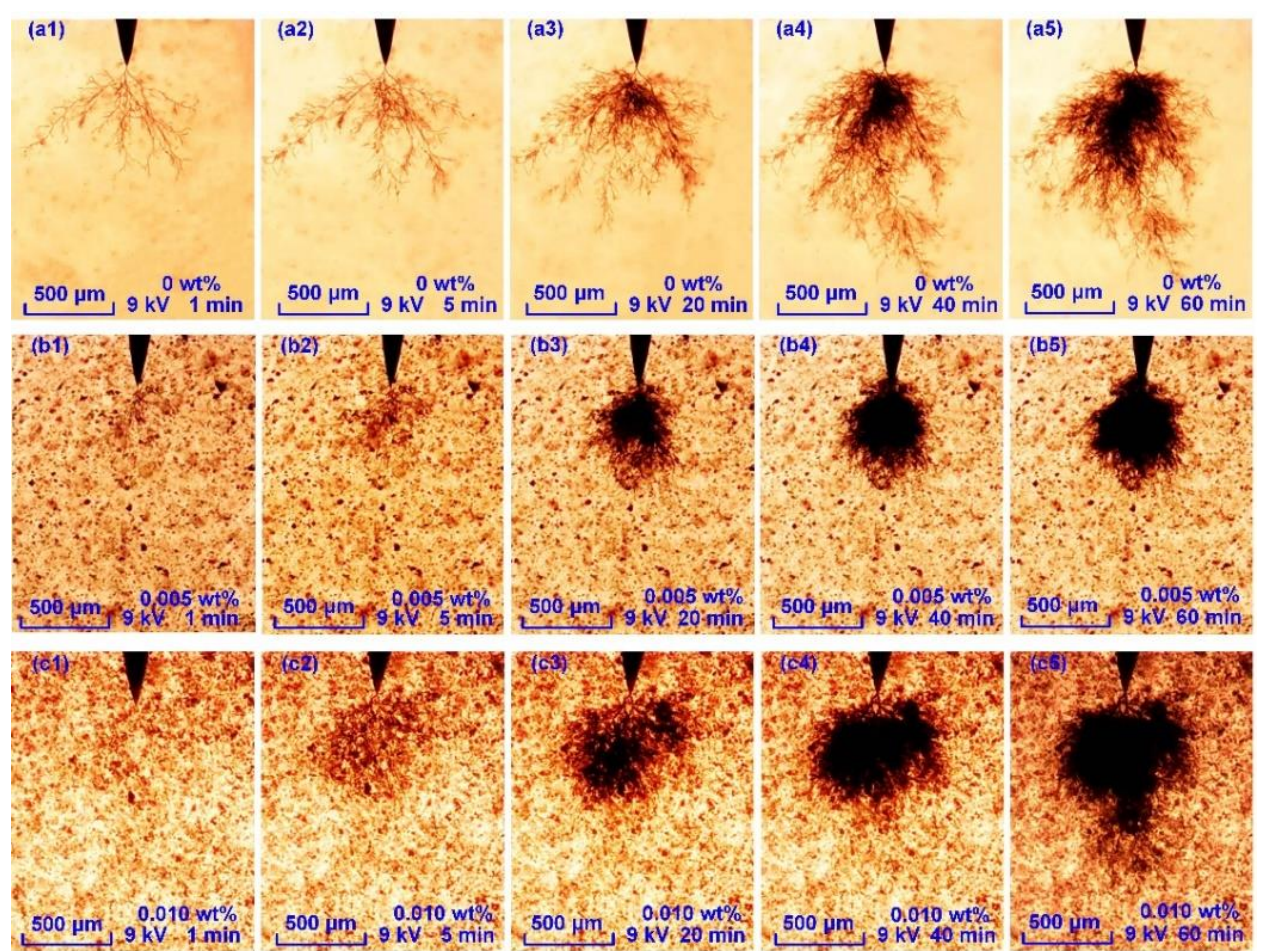

Figure 8. Tree growth process in graphene/silicone rubber (SIR) nanocomposites with different contents. (a1-a5) Tree growth in undoped SIR; (b1-b5) tree growth in nanocomposites with 0.005 wt \% and (c1-c5) tree growth in nanocomposites with $0.010 \mathrm{wt} \%$.

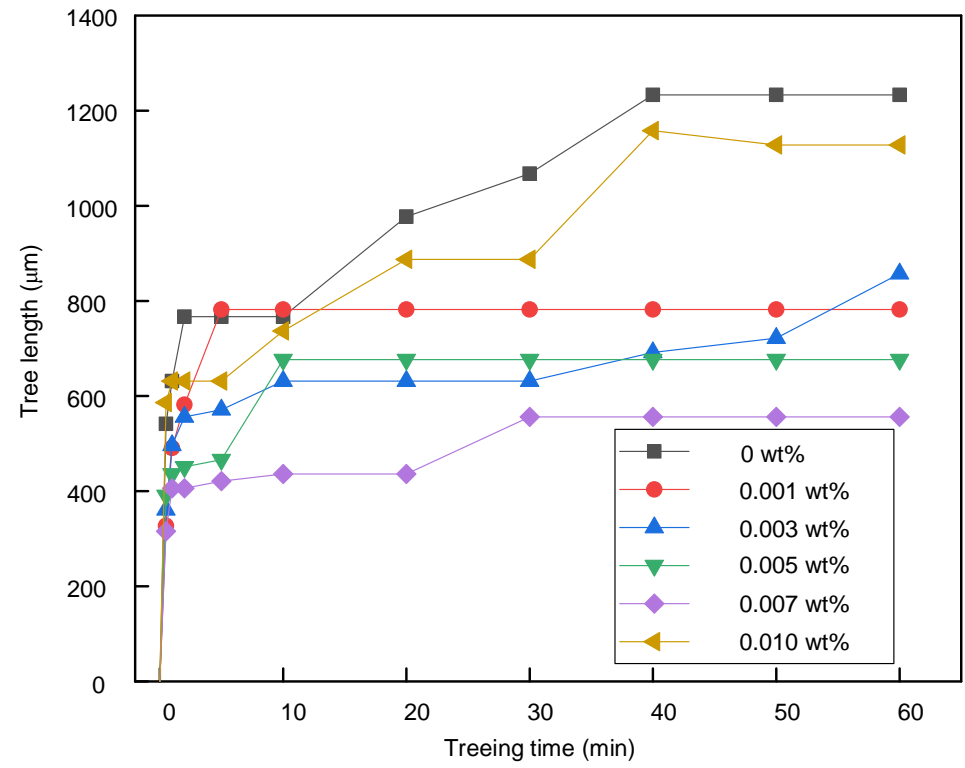

Figure 9. Tree growth process at different graphene contents.

During the experiments, nine samples of each graphene content were tested for $60 \mathrm{~min}$. The tree length at $60 \mathrm{~min}$ was calculated to analyze the inhibition effect of graphene. If the breakdown occurred within $60 \mathrm{~min}$, the length was calculated as $2 \mathrm{~mm}$. In the whole experiment, breakdown only occurred in samples with 0 and $0.010 \mathrm{wt} \%$. The box-plot of tree length at $60 \mathrm{~min}$ is shown in Figure 10. We found a nonlinear change in the average tree length. From 0 to $0.005 \mathrm{wt} \%$, the tree length decreased. From 0.005 to $0.010 \mathrm{wt} \%$, the tree length increased. The tree lengths in the samples 
with 0 and $0.010 \mathrm{wt} \%$ were more scattered. This was because breakdown occurred in some of these samples. 1 and 3 breakdowns occur in nine trees at 0 and $0.010 \mathrm{wt} \%$, respectively.

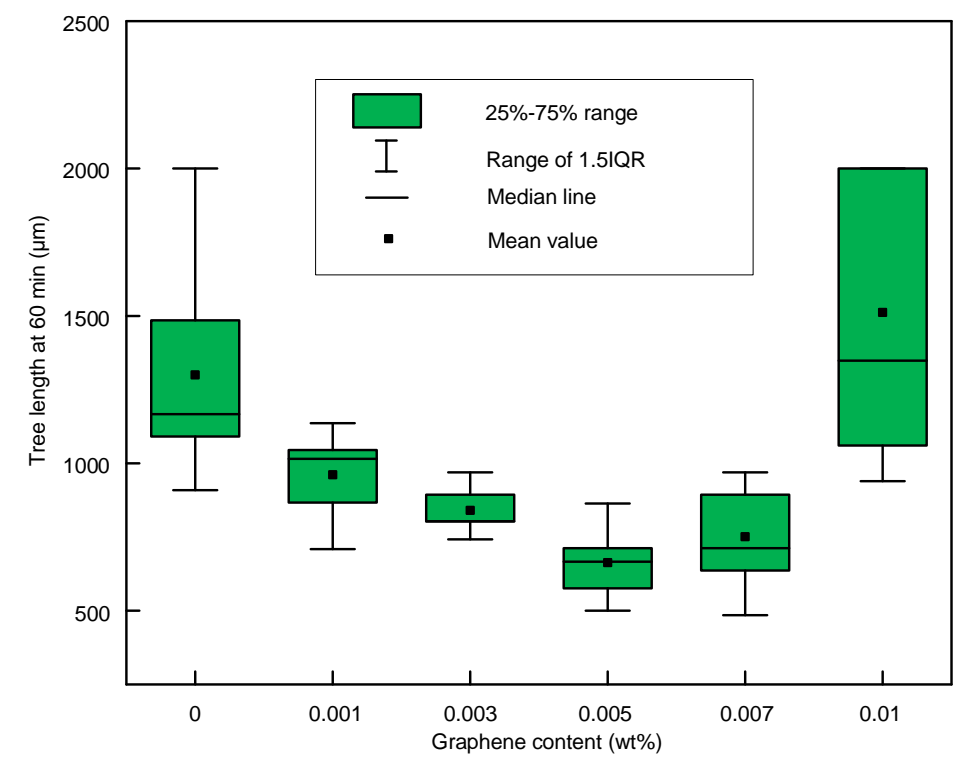

Figure 10. Tree length at $60 \mathrm{~min}$ with different graphene contents.

\section{Discussion}

\subsection{Tree Inception}

Under AC voltage, there is an electric field with altering direction. According to the theory proposed by Tanaka et.al., it is believed that there is an electron injection-extraction process near the needle tip [33]. Given the existence of traps in undoped SIR, some of these electrons are captured by traps near the needle tip after the injection. After the changing of electric field direction, some of these injected electrons will be extracted. In this repetitive injection and extraction process, collisions with molecular chains occur. If the electrons gain sufficient energy, this collision will break the molecular chains near the needle tip, producing lower molecular weight products and gas [33]. A partial discharge occurs if this region is big enough and the first tree channel will be triggered.

In the case of nanocomposites, the trapping-detrapping process is similar to what occurs in undoped SIR. When the electrons are injected into the sample, they will be captured by the traps around needle tip induced by the interface between SIR and graphene [26,34]. However, with graphene contents lower than $0.007 \mathrm{wt} \%$, the trap levels of graphene/SIR nanocomposites are higher than undoped SIR. As a result, the trapped electrons need more energy to detrap in these nanocomposites. A higher voltage is needed for the material degradation and the occurrence of partial discharge. As a result, tree inception voltage increases obviously in graphene/SIR nanocomposites, compared with an undoped SIR sample. However, the shorter distance between graphene nanoplatelets in samples at $0.010 \mathrm{wt} \%$ lower the trap levels, as shown in Figure 6. This indicates that the trapped electrons need lower energy to escape and gain sufficient energy [26,34]. As a result, there is a lower inception voltage in nanocomposites at $0.010 \mathrm{wt} \%$.

\subsection{Tree Growth}

According to the model proposed by Danikas et al. [20], the tree growth is inhibited by the particles in nanocomposites. In graphene/SIR nanocomposites, there are huge surface areas between the SIR and graphene nanoplatelets, even at low graphene content. As shown in Figure 11a, the graphene nanoplatelets are well dispersed in silicone rubber. In this condition, the graphene nanoplatelets will act as barriers during the treeing process. The tree channels will grow towards the graphene because 
of the electric field distortion and then grow along the interfaces. Because of the 2D structure and different orientations of graphene nanoplatelets, a bush tree forms rapidly after the inception and the tree length growth is inhibited, which is consistent with the treeing process in Figure 8b1-b5.
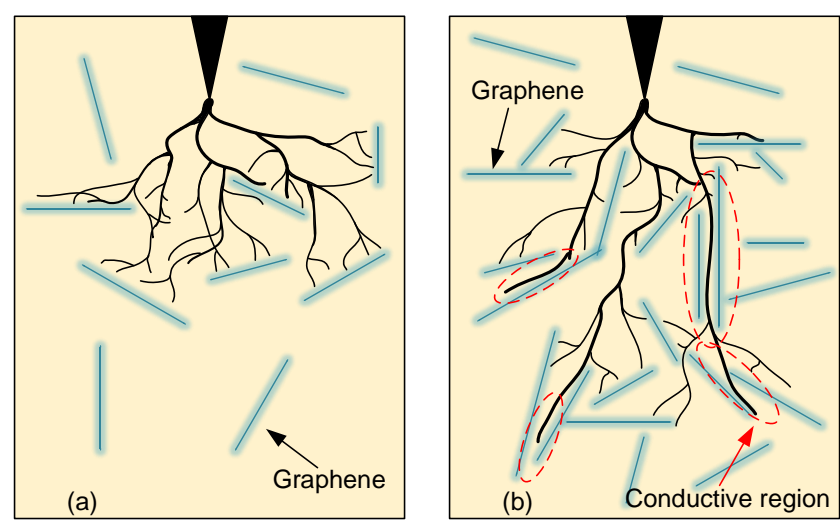

Figure 11. Effect of graphene nanoplatelets in the treeing process; (a) Inhibition effect of graphene and the formation of the bush tree; (b) Conductive regions at high graphene contents and their acceleration effect on tree growth.

However, the shorter distance between the nanoplatelets lower the dielectric strength in some regions inside the nanocomposites with higher content [34]. Because of the high conductivity of graphene nanoplatelets, these regions between the adjacent nanoplatelets may be conductive. The tree channels will go through these regions fast, as shown by the red circles in Figure 11b. With the increase of graphene content, the occurrence probability of the conductive regions becomes higher. This will lead to low degradation resistance, longer tree lengths and even breakdown at $0.010 \mathrm{wt} \%$.

\section{Conclusions}

Graphene nanoplatelets and SIR were employed to prepare nanocomposites with graphene content lower than $0.010 \mathrm{wt} \%$. SEM, conductivity and trap distribution characteristics were tested to examine the nanocomposites.

The results showed that the conductivity of SIR can be increased by the addition of graphene nanoplatelets. The trap distribution in SIR changes with the addition of graphene nanoplatelets. The shallow and deep trap levels in samples increase in nanocomposites with content ranging from 0.001 to $0.007 \mathrm{wt} \%$.

The electrical degradation was inhibited by the addition of graphene nanoplatelets at low contents. The average tree inception voltage increased after the addition of graphene nanoplatelets at contents of 0.001 to $0.007 \mathrm{wt} \%$. The tree structure in undoped SIR was a bush-branch tree, which changed to the bush tree structure in graphene/SIR nanocomposites. The tree length in graphene/SIR nanocomposites was inhibited at contents of 0.001 to $0.007 \mathrm{wt} \%$ and increased at $0.010 \mathrm{wt} \%$.

Author Contributions: Conceptualization, T.H. and B.D.; methodology, Y.G.; validation, B.D.; formal analysis, Y.X.; investigation, Y.X.; resources, T.H.; data curation, S.F.; writing—original draft preparation, T.H.; writing-review and editing, C.L. and Z.L.; visualization, J.S.; supervision, Y.G.; project administration, B.D.; funding acquisition, T.H.

Funding: This research was funded by Chinese National Natural Science Foundation under Grant Number 51707132, 51677127; and National Key Research and Development Program under Grant Number 2018 YFB0904400.

Acknowledgments: The authors thank the anonymous reviewers for their comments and the contribution of Fuyu Wang, Tingting Ma and Meng Tian from Tianjin University.

Conflicts of Interest: The authors declare no conflict of interest. 


\section{References}

1. Shit, S.C.; Shah, P. A review on silicone rubber. Natl. Acad. Sci. Lett. 2013, 36, 355-365. [CrossRef]

2. Wang, X.; Wang, C.C.; Wu, K.; Tu, D.M.; Liu, S.; Peng, J.K. An improved optimal design scheme for high voltage cable accessories. IEEE Trans. Dielectr. Electr. Insul. 2014, 21, 5-15. [CrossRef]

3. Ye, H.Y.; Fechner, T.; Lei, X.Z.; Luo, Y.; Zhou, M.Y.; Han, Z.Y.; Wang, H.T.; Zhuang, Q.K.; Xu, R.Y.; Li, D. Review on HVDC cable terminations. High Volt. 2018, 3, 79-89. [CrossRef]

4. Liu, T.; Hui, B.; Fu, M.; Hou, S.; Luo, B.; Wang, G. Experimental and simulation analysis of electrical breakdown for $220 \mathrm{kV}$ silicone rubber pre-moulded cable joints. In Proceedings of the 13th International Electrical Insulation Conference, Birmingham, UK, 16-18 May 2017.

5. Han, T.; Du, B.X.; Su, J.G. Electrical Tree Initiation and Growth in Silicone Rubber under Combined DC-Pulse Voltage. Energies 2018, 11, 764. [CrossRef]

6. Zhou, Y.X.; Liu, R.; Hou, F.; Zhang, X.; Xue, W.B. Morphology of electrical trees in silicon rubber. J. Electrost. 2013, 71, 440-448. [CrossRef]

7. Eichhorn, R.M. Treeing, a mechanism of breakdown in solid dielectrics. In Proceedings of the IEEE International Symposium on Electrical Insulation, Toronto, ON, Canada, 3-6 June 1990.

8. Shimizu, N.; Laurent, C. Electrical tree initiation. IEEE Trans. Dielectr. Electr. Insul. 1998, 5, 651-659. [CrossRef]

9. Bian, W.C.; Wang, W.X.; Yang, Y. A self-healing and electrical-tree-inhibiting epoxy composite with hydrogen-bonds and $\mathrm{SiO}_{2}$ particles. Polymers 2017, 9, 431. [CrossRef] [PubMed]

10. Chen, X.R.; Xu, Y.; Cao, X.L.; Gubanski, S.M. Electrical treeing behavior at high temperature in XLPE cable insulation samples. IEEE Trans. Dielectr. Electr. Insul. 2015, 22, 2015. [CrossRef]

11. Alapati, S.; Thomas, M.J. Influence of nano-fillers on electrical treeing in epoxy insulation. IET Sci. Meas. Technol. 2012, 6, 21-28. [CrossRef]

12. Yamano, Y. Control of electrical tree at initiation stage in LDPE by mixed addition of $\mathrm{Al}_{2} \mathrm{O}_{3}$ nano-particle and azobenzoic compound. IEEE Trans. Dielectr. Electr. Insul. 2014, 21, 209-216. [CrossRef]

13. Sridhar, A.; Thomas, M.J. Electrical treeing in polyethylene: Effect of nano fillers on tree inception and growth. In Proceedings of the 2010 International Conference on High Voltage Engineering and Application, New Orleans, LA, USA, 11-14 October 2010.

14. Chi, X.H.; Gao, J.G.; Zhang, X.H. Electrical tree propagating characteristics of polyethylene/nano-montmorillonite composites. IEEE Trans. Dielectr. Electr. Insul. 2015, 22, 1530-1536. [CrossRef]

15. Du, B.X.; Han, T.; Su, J.G. Tree characteristics in silicone rubber $/ \mathrm{SiO}_{2}$ nanocomposites under low temperature. IEEE Trans. Dielectr. Electr. Insul. 2014, 21, 503-510. [CrossRef]

16. Jamil, A.A.A.; Bashir, N.; Ahmad, M.H.; Arief, Y.Z.; Kamarol, M.; Mariatti, M. Electrical treeing initiation and propagation in silicone rubber nanocomposites. In Proceedings of the 2013 IEEE Conference on Electrical Insulation and Dielectric Phenomena, Shenzhen, China, 20-23 October 2013.

17. Hafiz, M.; Fairus, M.; Mariatti, M.; Kamarol, M. A comparative study on electrical tree growth in silicone rubber containing nanoalumina and halloysite nanoclay. IEEE Access 2019, 7, 24452-24462. [CrossRef]

18. Tanaka, T.; Kozako, M.; Fuse, N.; Ohki, Y. Proposal of a multi-core model for polymer nanocomposite dielectrics. IEEE Trans. Dielectr. Electr. Insul. 2005, 12, 669-681. [CrossRef]

19. Vogelsang, R.; Farr, T.; Frohlich, K. The effect of barriers on electrical tree propagation in composite insulation materials. IEEE Trans. Dielectr. Electr. Insul. 2006, 13, 373-382. [CrossRef]

20. Danikas, M.G.; Tanaka, T. Nanocomposites-A review of electrical treeing and breakdown. IEEE Electr. Insul. Mag. 2009, 25, 19-25. [CrossRef]

21. Yang, H.; Yao, X.F.; Zheng, Z.; Gong, L.H.; Yuan, L.; Yuan, Y.N.; Liu, Y.H. Highly sensitive and stretchable graphene-silicone rubber composites for strain sensing. Compos. Sci. Technol. 2018, 167, 371-378. [CrossRef]

22. Zhang, G.W.; Wang, F.Z.; Dai, J.; Huang, Z.X. Effect of functionalization of graphene nanoplatelets on the mechanical and thermal properties of silicone rubber composites. Materials 2016, 9, 92. [CrossRef]

23. Wang, Y.; Qiu, X.; Zheng, J. Effect of the sheet size on the thermal stability of silicone rubber-reduced graphene oxide nanocomposites. J. Appl. Polym. Sci. 2019, 136, 47034. [CrossRef] 
24. Sanchez-Hidalgo, R.; Blanco, C.; Menendez, R.; Verdejo, R.; Lopez-Manchado, M.A. Multifunctional silicone rubber nanocomposites by controlling the structure and morphology of graphene material. Polymers 2019, 11, 449. [CrossRef]

25. Li, Z.L.; Du, B.X.; Yang, Z.R.; Han, C.L. Temperature dependent trap level characteristics of graphene/LDPE nanocomposites. IEEE Trans. Dielectr. Electr. Insul. 2018, 25, 137-144. [CrossRef]

26. Li, Z.L.; Su, J.G.; Du, B.X.; Hou, Z.H.; Han, C.L. Inhibition effect of graphene on space charge injection and accumulation in low-density polyethylene. Nanomaterials 2018, 8, 956. [CrossRef]

27. Du, B.X.; Su, J.G.; Tian, M.; Han, T.; Li, J. Understanding trap effects on electrical treeing phenomena in EPDM/POSS composites. Sci. Rep. 2019, 8, 8481. [CrossRef]

28. Du, B.X.; Yang, Z.R.; Li, Z.L.; Li, J. Temperature-dependent nonlinear conductivity and carrier mobility of silicone rubber/SiC composites. IEEE Trans. Dielectr. Electr. Insul. 2008, 25, 1080-1087. [CrossRef]

29. Han, T.; Du, B.X.; Ma, T.T.; Wang, F.Y.; Gao, Y.; Lei, Z.P.; Li, C.Y. Electrical Tree in HTV Silicone Rubber with Temperature Gradient under Repetitive Pulse Voltage. IEEE Access 2019, 7, 41250-41260. [CrossRef]

30. Simmons, J.G.; Tam, M.C. Theory of isothermal currents and the direct determination of trap parameters in semiconductors and insulators containing arbitrary trap distributions. Phys. Rev. B 1973, 7, 3706-3712. [CrossRef]

31. Kindersberger, J.; Lederle, C. Surface charge decay on insulators in air and sulfurhexafluorid-Part II: Measurements. IEEE Trans. Dielectr. Electr. Insul. 2008, 15, 949-957. [CrossRef]

32. Li, C.; Lin, C.; Chen, G.; Tu, Y.; Zhou, Y.; Li, Q.; Zhang, B.; He, J. Field-dependent charging phenomenon of HVDC spacers based on dominant charge behaviors. Appl. Phys. Lett. 2019, 114, 202904. [CrossRef]

33. Tanaka, T.; Greenwood, A. Effects of space charge injection and extraction on tree initiation in polyethylene. IEEE Trans. Power Appar. Syst. 1978, 97, 1749-1759. [CrossRef]

34. Alapati, S.; Thomas, M.J. Electrical Treeing and the Associated PD Characteristics in LDPE Nanocomposites. IEEE Trans. Dielectr. Electr. Insul. 2012, 19, 697-704. [CrossRef] 